\title{
Associations between management practices and within-pen prevalence of calf diarrhea and respiratory disease on dairy farms using automated milk feeders
}

\author{
Catalina Medrano-Galarza, ${ }^{*} \dagger^{1}$ Stephen J. LeBlanc, ${ }^{\star} \dagger$ Andria Jones-Bitton, ${ }^{*}$ Trevor J. DeVries, $\dagger \ddagger$ \\ Jeffrey Rushen,§ Anne Marie de Passillé,§ Marcia I. Endres,\# and Derek B. Haley*† \\ *Department of Population Medicine, Ontario Veterinary College, \\ †Campbell Centre for the Study of Animal Welfare, and \\ ‡Department of Animal Biosciences, Ontario Agricultural College, University of Guelph, Guelph, ON, N1G 2W1, Canada \\ §Faculty of Land and Food Systems, University of British Columbia, Agassiz, BC, V6T 1Z4, Canada \\ \#Department of Animal Science, University of Minnesota, St. Paul 55108-6118
}

\section{ABSTRACT}

Data on management practices used with automated milk feeders $(\mathrm{AMF})$ are needed to identify factors associated with calf health in these systems. The objectives of this observational, longitudinal, cross-sectional study were to estimate the prevalence of calf diarrhea (CD) and bovine respiratory disease (BRD), and to identify factors associated with prevalence of these diseases at the pen level on dairy farms feeding milk to group-housed calves with AMF. Seventeen dairy farms with AMF in Ontario, Canada, were visited 4 times, seasonally, over $1 \mathrm{yr}$. The clinical health of all calves $(\mathrm{n}=1,488)$ in pens $(\mathrm{n}=35)$ with $\mathrm{AMF}$ was scored to identify the number of calves with $\mathrm{CD}$ and BRD. Data on calf, feeder, and pen management practices were analyzed using generalized linear mixed regression models for each disease. Overall calf-level prevalence of $\mathrm{CD}$ and BRD were 23 and 17\%, respectively. Median (interquartile range, IQR) within-pen prevalence of CD and BRD were $17 \%$ (7 to $37 \%$ ) and $11 \%$ (0 to $28 \%$ ), respectively. Median age (IQR) for diarrheic calves was $25 \mathrm{~d}$ (16 to $42 \mathrm{~d}$ ), and for calves with BRD was $43 \mathrm{~d}$ (29 to $60 \mathrm{~d})$. Factors associated with lower within-pen prevalence of $\mathrm{CD}$ were the administration of vitamin $\mathrm{E}$ and selenium at birth [odds ratio $(\mathrm{OR})=0.56 ; 95 \%$ confidence interval (CI): 0.32 to 0.99 , feeding of probiotics (OR $=0.44,95 \%$ CI: 0.22 to 0.93$)$, and adding fresh bedding every 2 to $3 \mathrm{~d}(\mathrm{OR}=0.43 ; 95 \%$ CI: 0.24 to 0.76 ) compared with every 7 or more days. In contrast, sharing air with older cattle $(>9$ mo old) was associated with increased within-pen prevalence of CD $(\mathrm{OR}=4.54,95 \% \mathrm{CI}: 1.88$ to 10.52$)$. Additionally, to-

Received August 23, 2017.

Accepted November 16, 2017.

${ }^{1}$ Corresponding author: cata.medrano@outlook.com tal bacteria counts $\geq 100,000 \mathrm{cfu} / \mathrm{mL}$ in milk samples taken from the AMF mixing jar were associated with increased within-pen prevalence of CD during the summer visit (OR $=3.34 ; 95 \%$ CI: 1.31 to 8.54$)$. Increased total solids in milk or milk replacer $(\mathrm{OR}=0.48,95 \%$ CI: 0.27 to 0.85 ) and feeding whole milk versus milk replacer $(\mathrm{OR}=0.29,95 \%$ CI: 0.11 to 0.75$)$ were associated with lower within-pen prevalence of BRD. Factors associated with greater within-pen prevalence of BRD were sharing air with weaned cattle up to 8 mo old $(\mathrm{OR}=3.21,95 \% \mathrm{CI}: 1.26$ to 8.16$)$, and greater depth of the wet bedding pack. The use of maternity pens for reasons other than just calving was associated with increased prevalence of both $\mathrm{CD}$ and $\mathrm{BRD}(\mathrm{OR}=1.85$, 95\% CI: 1.03 to 3.33 ; OR $=2.61,95 \%$ CI: 1.21 to 5.58 , respectively). These results suggest that isolation from older animals and frequent cleaning of the feeder and pen may help to reduce disease prevalence in grouphoused calves fed with an AMF.

Key words: dairy calf, morbidity, automated feeding, group housing

\section{INTRODUCTION}

In North America, a growing proportion of calves is group-housed and fed with automated milk feeders (AMF) during the milk-feeding period (USDA, 2016). Medrano-Galarza et al. (2017a) reported that $36 \%$ of 670 dairy farms that participated in a survey on calf rearing practices across Canada housed calves in groups and $16 \%$ fed milk through AMF machines. The adoption of AMF is increasing steadily among producers (Medrano-Galarza et al., 2017a) as a way to improve working conditions and reduce physical labor while facilitating feeding high volumes of milk in multiple portions throughout the day to group-housed calves (Medrano-Galarza et al., 2017b). Nevertheless, 
some producers attribute difficulties with AMF (i.e., perceived high morbidity and mortality) to the feeders themselves and the type of housing (Endres, 2013), with some producers switching back to individual housing and feeding (Medrano-Galarza et al., 2017a). Producers perceive individual housing and individual feeding as a way to reduce disease transmission (Medrano-Galarza et al., 2017b) by limiting direct contact between calves, which has also been recommended by veterinarians (Callan and Garry, 2002; Stull and Reynolds, 2008). Observational studies in Sweden have shown the risk of bovine respiratory disease (BRD) to be significantly higher for AMF-fed calves housed in groups of 6 to 30 calves/pen compared with manually fed calves housed individually (Lundborg et al., 2003, 2005; Svensson et al., 2003) or in groups of 3 to 8 calves/pen (Lundborg et al., 2005). The severity of calf diarrhea (CD) cases was significantly higher in AMF-fed calves in large groups than in individually housed calves (Svensson et al., 2003).

For Swedish farms feeding calves with an AMF, overall calf-level incidence risk of CD and BRD, up to $90 \mathrm{~d}$ of age, were 9 and 14\%, respectively (Svensson et al., 2003). Additionally, Svensson and Liberg (2006) controlled group size in pens with AMF (6 to 9 calves vs. 12 to 18 calves) and found that within-pen incidence risk of CD and BRD ranged from 1 to $42 \%$, and from 0 to $54 \%$, respectively (median incidence in small groups: $\mathrm{CD}=13 \%$ and $\mathrm{BRD}=18 \%$, and in large groups: $\mathrm{CD}$ $=20 \%$ and $\mathrm{BRD}=31 \%$ ). However, only the risk of respiratory disease was significantly higher for calves housed in large groups compared with those housed in small groups.

Research focused on the health impacts of raising calves with AMF systems and management practices other than group size is scarce. In North America, an observational study across farms in the US Midwest is the only available published research on this topic (Jorgensen et al., 2017). In that study, researchers found associations between individual calf health scores (e.g., attitude, temperature, hind-end dirtiness score) and management practices regarding milk feeding plan, cleanliness of the AMF, and ventilation. To be able to support farmers by helping users of AMF improve their management practices and by providing information to guide decision-making of future adopters of AMF systems, it is essential to estimate disease frequency and determinants of calf health under AMF systems. Hence, the objectives of the present study were to estimate prevalence of $\mathrm{CD}$ and $\mathrm{BRD}$, and to identify factors associated with prevalence of these diseases at the pen level on dairy farms feeding milk to group-housed calves with AMF in southern Ontario, Canada.

\section{MATERIALS AND METHODS}

This observational, longitudinal, cross-sectional study was reviewed and approved by the University of Guelph Animal Care Committee (Animal Use Protocol \#3212).

\section{Sample Size Estimation}

During planning stages, and based on research done on farms with AMF in Sweden (Svensson and Liberg, 2006; the only research available at the time), we made the assumption that the mean within-pen prevalences of CD and BRD were 10 and $20 \%$, respectively (SD of $10 \%$ ), in small (as defined above) groups and 20 and $30 \%$, respectively (SD of $15 \%$ ), in large groups. Using these assumptions, we estimated a total sample size of 52 pens for a power of $80 \%$ and a confidence level of 95\% to be able to detect a difference of $10 \%$ (WINPEPI statistical program, version 11.62; Abramson, 2011). The estimated sample size was adjusted for clustering by farm (with an estimated average cluster size of 2 pens per farm) and an assumed intraclass correlation of 0.2. This gave an estimated sample size of 64 pens ( $\sim 32$ farms) when analyzing the effect of one exposure variable.

\section{Enrollment of Farms and Farm Visits}

A convenience sample of commercial dairy farms was obtained from a list of volunteer farms that expressed interest in participating in this study after completing an online survey on calf management practices (Medrano-Galarza et al., 2017a). Farms were initially selected based on location (no more than $2.5 \mathrm{~h}$ drive from the University of Guelph, Ontario, Canada) and willingness to complete a short questionnaire on calving, newborn calf, group-pen, and AMF management practices. Farms fulfilling the location criterion were contacted by telephone to confirm their willingness to participate and to schedule the first farm visit. Of the farms with AMF that completed the online survey, 73 indicated that they were interested in participating in the present study and provided their contact information. Of these, 32 farms were located in the province of Ontario, Canada. Only 18 farms fulfilled the location criterion, 17 of which agreed to participate and were enrolled.

Each farm was visited 4 times, once per season, over $1 \mathrm{yr}$, starting in the fall of 2015 and ending in the summer of 2016. Fall farm visits were carried out between November 2 and December 1, 2015; winter visits occurred between February 3 and March 16, 2016; spring 
Table 1. Calf health scoring system used to classify health status in calves housed in group pens and fed through automated milk feeders in 17 dairy farms in southern Ontario

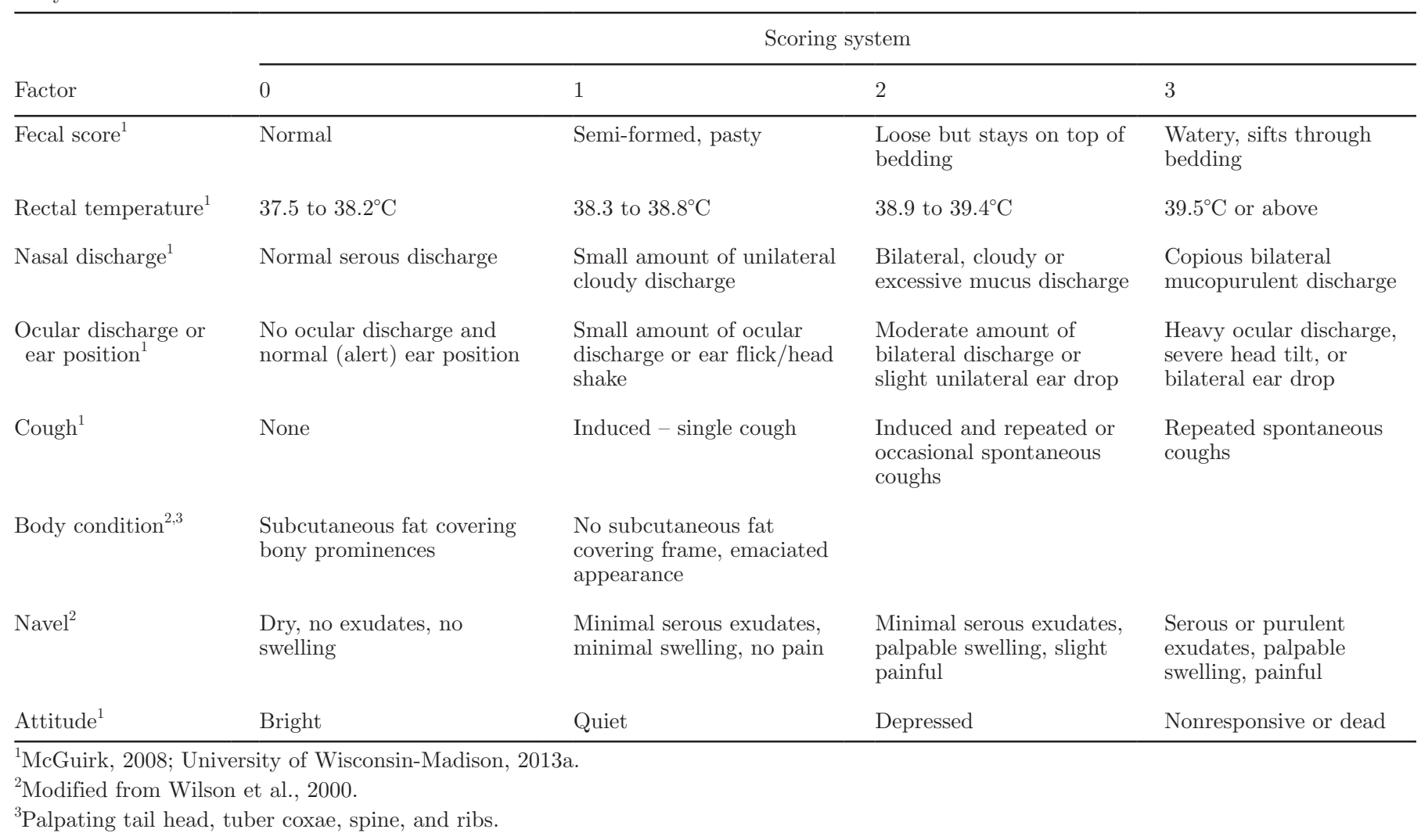

visits between April 19 and May 30, 2016; and summer visits between August 3 and September 6, 2016. All group pens with AMF that were being used (i.e., housing calves) on the day of the visit were included in the study. A total of $34,35,33$, and 35 group pens with AMF were evaluated during each seasonal visit, respectively. Before each visit, producers were contacted by telephone, text, or email to set the visit date. All measurements were performed by the same person (first author), with the help of at least 1 volunteer per visit.

\section{Measurements at the Calf Level}

The health of all calves (heifers and bulls) housed in group pens with AMF was scored during each of the 4 seasonal visits to each farm, using the fecal and calf respiratory scoring charts developed by McGuirk (2008) and the University of Wisconsin-Madison (2013a). Because calves were moved to other pens after being weaned in between visits, only one health assessment was done for each calf.

Table 1 summarizes the health scoring charts used in this study. The fecal scoring chart consisted of a 4-point scale that, ultimately, was dichotomized such that a score of 0 or 1 indicated absence of CD, and a score of
2 or 3 indicated the presence of CD. The respiratory scoring chart consisted of a conjunct evaluation of rectal temperature, nasal discharge, ocular discharge, ear position, and cough parameters. Each parameter was graded using a 4-point scale where 0 was considered normal and 3 severely abnormal. Scores for each parameter were added, and calves with a total respiratory score $>4$ were considered to have BRD (McGuirk and Peek, 2014).

In addition, body condition, navel, and attitude were evaluated (Table 1). Body condition was evaluated using 2-point scoring (modified from Wilson et al., 2000), where 0 was considered a satisfactory condition, and 1 was considered poor condition (very thin calf). Navel (modified from Wilson et al., 2000) and attitude were evaluated using a 4-point scale, where a score of 0 was considered normal, and a score of 3 was considered severely abnormal.

The age of each calf during each visit was obtained using farm birth records, and the age of introduction to the pen with the AMF was calculated using the birth date of each calf and the individual start date in the AMF. The latter was directly obtained from the AMF handheld terminal or screen, which records and stores information on each calf (e.g., start date on the feeder, 
number of days on the feeder to date, milk feeding plan assigned).

\section{Measurements at the Pen Level}

Stocking Density and Range in Calf Age. The width and length of the lying surface (surface with bedding) were measured during each farm visit using a measuring tape. These measurements were the same per pen across visits except for 3 farms. Lying area per calf (in $\mathrm{m}^{2}$ ) was calculated by dividing the total area by the total number of calves housed in the pen during each visit. Maximum age difference (in days) among calves for each pen during each visit was calculated by subtracting the age of the youngest calf from the age of the oldest calf. In addition, we recorded whether the pen was located against an outer wall.

Nesting Score. Each pen was assigned an overall nesting score. A 3-point scale was used based on the ability of calves to nestle into the bedding, as described by Lago et al. (2006). At least $75 \%$ of calves in each pen were observed while lying down (ideally at the beginning of the visit) and assigned an individual nesting score. A score of 1 indicated that the calf was lying on top of the bedding with legs exposed; a score of 2 indicated that the calf was slightly able to nestle into the bedding, but legs were partially exposed above the bedding; and a score of 3 indicated that a calf was nestling deeply into the bedding with legs not visible. Then, the most frequently observed score within a pen (i.e., mode) was the overall score assigned to the pen.

Wetness of the Bedding. To evaluate the wetness of the bedding, a paper towel scoring system, developed by the Dairy Research Cluster (2011), and DM estimation were used. The former was modified to be able to evaluate a group pen rather than a single stall as described in the Dairy Research Cluster protocol. Eight spots across the entire pen were evaluated for wetness following an imaginary "W" pattern (mimicking methodologies used on estimation of DM of pasture-based systems; e.g., Pennsylvania State University, 2007; Supplemental Figure S1; https://doi.org/10.3168/jds .2017-13733). A new paper towel folded in 4 (Bounty, Procter \& Gamble, Cincinnati, OH) was placed each time on top of the bedding on each of the 8 sampling spots (making sure the towel was not placed on top of calf feces). Three seconds of pressure was applied onto the towel by kneeling down on it, and the wetness score was recorded (dry, wet, or very wet). The percentage of dry spots across the pen was used as an estimate of the percentage of dry bedding surface per pen.

A representative sample of the top bedding for each pen was collected to determine DM. A handful of the top of the bedding material was collected from each of the same 8 sampling spots used for the paper towel scoring system. The bedding from each spot was collected in a resealable plastic bag and stored at $-20^{\circ} \mathrm{C}$ until all samples for the season were collected. Then, bedding samples were defrosted over a 24 -h period at $4^{\circ} \mathrm{C}$, and samples were weighed, oven-dried at $60^{\circ} \mathrm{C}$ for $48 \mathrm{~h}$, and reweighed to determine DM.

Bedding Depth. The depth (cm) of the wet bedding pack (manure-saturated bedding) and of the dry layer of the bedding were measured 8 times across the pen (at the same spots as the paper towel test). A garden spoon was used to dig a hole to the pen floor, and a measuring tape was used to measure depth. The average depths of the wet bedding pack and of the dry layer of the bedding were calculated for each pen using the values obtained for each of the 8 spots evaluated. In addition, the type of bedding material was recorded.

\section{Measurements Related to the AMF}

Information on the milk feeding plan-milk type (whole vs. milk replacer), start milk allowance [volume (L) offered per calf on the first day in the group pen with the AMF], peak milk allowance [maximum volume (L/d) offered per calf during the milk feeding period], latency to peak (number of days to reach the peak milk allowance), length of peak (number of days calves were allowed to drink the maximum volume), the weaning process used [age at weaning, duration (d) of weaning, and age when weaned], and solids (g) per liter of water when milk replacer was used-was obtained at each visit directly from the AMF. Hygienic quality of the milk fed to calves was assessed by bacteriological culture of the milk. Under the most aseptic conditions possible, samples of milk or milk replacer were collected after a portion of milk was automatically prepared in the mixing jar. The first sample was taken directly from the jar using a $50-\mathrm{mL}$ sterile syringe to collect the milk and place it in a $15-\mathrm{mL}$ sterile tube; then, another sample of milk was taken at the end of the hose(s), which was previously detached from the teat, using a $15-\mathrm{mL}$ sterile tube directly to collect the milk coming out of the hose. Milk samples were immediately placed in an insulated container (Coleman Company Inc., Brampton, ON, Canada) and delivered the same day to the Animal Health Laboratory (AHL; University of Guelph, Guelph, ON, Canada) for bacteriological analysis [total bacteria count (TBC) and total coliform count (TCC)]. The samples were processed according to AHL standard operating procedure. Briefly, serial dilutions of each sample were made in PBS. One milliliter of each dilution was plated on Petrifilm (3M Inc., 
St. Paul, MN) and incubated at $35^{\circ} \mathrm{C}$ under aerobic conditions. The TCC were obtained after $24 \mathrm{~h}$ of incubation, followed by TBC after $48 \mathrm{~h}$ of incubation.

The TBC and TCC were dichotomized as acceptable or not acceptable based on suggested limits of bacteria counts in milk fed to calves (TBC: $<100,000 \mathrm{cfu} / \mathrm{mL}$; TCC: <10,000 cfu/mL; McGuirk and Collins, 2004). Another sample of milk was collected from the mixing jar to determine the percentage total solids using a Brix Refractometer (Atago PAL-1-3810, ITM Instruments Inc., Newmarket, ON, Canada). Briefly, 2 to 3 drops of vortexed milk was placed on the measurement prism and a reading was obtained after $3 \mathrm{~s}$. The refractometer was calibrated before each use and cleaned between samples. Additionally, when milk replacer was being fed, a sample of the powder was collected to be able to create a standard curve with Brix readings at different concentrations of milk replacer solution and adjust the Brix readings from the samples collected at the farms (University of Wisconsin-Madison, 2013b).

\section{Questionnaires and Measurements at the Farm Level}

Farm-level measurements were collected throughout each of the 4 seasonal visits by direct observation and questionnaires. Direct observation was used to collect information on type of ventilation (natural ventilation, positive-pressure ventilation system, or both) used in the facilities where calves were housed. In addition, when a positive-pressure ventilation system was used, the source of the air coming into the calf barn was recorded (e.g., from outdoors, attic, or cow barn). Two questionnaires were used to collect information on calving, colostrum, pen dynamics, bedding, and AMF management practices. The first questionnaire was handed to each producer on the first visit to the farm and producers were asked to have it completed by the second visit. The second questionnaire, which was focused on pen management practices and calf movements between pens, was completed by face-to-face interview conducted by the first author at the fourth visit. Questionnaires are available as Supplemental Data (https:// doi.org/10.3168/jds.2017-13733). In addition, we asked producers to keep records of treatments for disease and mortality (i.e., calves that died excluding stillbirths) during the study period.

\section{Data Management and Statistical Analysis}

Calf-, pen-, and farm-level data were entered into Excel (Microsoft Corp., Redmond, WA). All Excel sheets were imported into SAS version 9.3 (SAS Institute Inc., Cary, NC). Calf-level, within-pen, and within-herd prevalence of $\mathrm{CD}$ and $\mathrm{BRD}$ were calculated using the
SUMMARY procedure in SAS 9.3. The within-pen prevalence SAS data set was merged (by season, farm, and pen) with pen- and farm-level data sets.

Generalized linear mixed regression models (PROC GLIMMIX in SAS) with binomial distribution and the "events/trials" syntax were used for analysis (Schabenberger, 2005). The 2 outcomes of interest were the number of diarrhea cases in a pen (events) out of the total number of calves in that pen (trials), and the number of BRD cases in a pen (events) out of the total number of calves in that pen (trials). Therefore, the models assessed the odds of greater prevalence of disease. Farm was included as a random effect to account for clustering (i.e., observations within a farm might not be independent). Pen nested within farm was included as a residual-side random component using the autoregressive variance-covariance structure to adjust for repeated measures within pen. Seasonal visit was included as a fixed effect. Because of the large number of factors being evaluated, independent variables were grouped into 4 logical clusters and separate models constructed (Dohoo et al., 2009) based on management areas: calving and newborn management; milk feeding plan; AMF calibration and cleaning practices; and pen management and barn features (Supplemental Tables S1 to S4, respectively; https://doi.org/10.3168/ jds.2017-13733). The association of bacteria counts in milk (Supplemental Table S5; https://doi.org/10.3168/ jds.2017-13733) and prevalence of CD and BRD was examined separately, because if included in the model for AMF cleaning practices, it would become an intervening variable (Dohoo et al., 2009).

The linearity of continuous predictors was evaluated by examining the quadratic term (Dohoo et al., 2009). If the linearity assumption could not be fulfilled, the variable was categorized based on quartiles. The correlation between continuous and categorical variables was evaluated to assess collinearity using Pearson and Spearman correlation coefficients, respectively. If the correlation was $\geq 0.8$, the least significant variable when tested in the univariable analysis was removed. Management factors with $P<0.3$ in the univariable analysis were offered to the multivariable model. For each multivariable model, a variable was considered a confounder when the difference between coefficients of the full model (controlling for potential confounder) and reduced model (without the confounder) was $>20 \%$ (Dohoo et al., 2009). The model was reduced using backward elimination and variables remained in the model when $P<0.1$. Plausible interactions between independent variables were tested and remained in the model if significant $(P<0.05)$. Interpretation of interaction terms was done by calculating, comparing, and plotting the least squares means estimates of the 
prevalence of disease for the conditional effects of interactions using PROC PLM in SAS (SAS, 2017; UCLA, 2017). Least squares means estimates of the prevalence of disease $(x)$ were used to calculate adjusted prevalence $(A P)$ values using the formula

$$
A P=100 \times \frac{1}{1+e^{-x}} .
$$

The assumptions of normality and homoscedasticity of BLUPS (best residuals unbiased predictors) was assessed graphically. Outliers were examined graphically by plotting Pearson residuals with the predicted probability of the outcome. Removal of extreme observations did not affect the models, thus we chose to leave them in the final models.

Using producers' treatment and mortality records, which only included calves born and kept during the year the study was carried out (September 22, 2015, to September 21, 2016), herd-level incidence risks of being treated for each disease were calculated as the number of calves treated for the first time up to $90 \mathrm{~d}$ of age (risk period) divided by the total number of calves at risk (half of withdrawals were subtracted from the denominator; Dohoo et al., 2009). Withdrawals included any calf that was not followed for the entire risk period and was not treated for the disease. Herd-level incidence risks of mortality (i.e., all deaths excluding stillbirths) were calculated similarly.

\section{RESULTS}

\section{Farm Features and AMF and Group Pen Setup}

Median herd size was 115 milking cows (range: 70 to 330 milking cows). Eleven of the 17 farms housed their milking cows in freestalls and used a conventional milking parlor, 4 farms housed cows in freestalls with automatic milking systems, 1 farm housed cows in a bedded-pack barn with automatic milking systems, and 1 farm housed cows in tie-stalls with a portable milking system. Ten farms exclusively raised heifer calves, and 7 farms also raised bulls to be sold as dairy beef or red veal. The majority of the farms $(76 \%)$ had only Holstein cattle, whereas 4 of the 7 farms raising bulls bred some Holstein cows with beef breeds.

The median year when farms installed AMF was 2010 (range: 2003 to 2015). The ratio of AMF machines to farms was 1:1 for 13 farms, and 2:1 for 4 farms. The most common ratio of pens to AMF was 2:1 (i.e., 1 feeder delivered milk into 2 feeding stations - typically one for calves under $30 \mathrm{~d}$ of age and one for calves above $30 \mathrm{~d}$ of age and a couple of weeks after being weaned - each located in 2 separate pens), although 1 pen housing all calves per feeder was present too (Supplemental Table S6; https://doi.org/10.3168/jds.2017-13733).

Median daily milk allowance during the period between birth and introduction to the group pen with AMF was $6 \mathrm{~L} / \mathrm{d}$ (range: 4 to $9 \mathrm{~L} / \mathrm{d}$ ). Median peak milk allowance per day once calves were automatically fed was $10 \mathrm{~L} / \mathrm{d}$ (range: 6 to $15 \mathrm{~L} / \mathrm{d}$ ). Between 82 and $88 \%$ of the farms fed milk replacer to calves through the AMF (varied by season), which was offered at a set concentration that ranged from 140 to $170 \mathrm{~g} / \mathrm{L}$. When the measured percentage of TS was compared with the expected percentage of TS (based on the set concentration), the median of the difference was $-2.3 \%(95 \%$ CI: -2.8 to -1.7 ; range: -8.4 to $4.8 \%$; $P<0.001)$. Only 1 farm (6\%) implemented a partial "all-in/all-out" stocking approach, where the producer had 2 rooms (each with $1 \mathrm{AMF}$ and 2 pens) so when 1 room was full, no more calves were added as calves left the room. The rest of farms (16 of 17) used a continuous flow approach. The distribution of independent variables is presented in Supplemental Tables S1 to S5; https://doi .org/10.3168/jds.2017-13733).

\section{Prevalence of Disease and Mortality}

Prevalence of $\boldsymbol{C D}$ and $\boldsymbol{B R} \boldsymbol{D}$. Of the 1,488 calves assessed at a single point in time, $23 \%$ had CD $(\mathrm{n}=337)$ and $17 \%$ had BRD ( $\mathrm{n}=246)$. Among CD cases, $32 \%$ had a BCS of 1 (indicative of emaciated appearance), $5 \%$ had an abnormal attitude score of 2 or 3 (indicating depression or a nonresponsive status, respectively), $5 \%$ had an abnormal navel score (2 or 3), and $16 \%$ had fever (rectal temperature $\geq 39.5^{\circ} \mathrm{C}$ ). Within BRD cases, $26 \%$ of calves had a BCS of $1,10 \%$ had an abnormal attitude score of 2 or 3, $1 \%$ had an abnormal navel, and $42 \%$ had fever.

The median age of calves with diarrhea was $25 \mathrm{~d}$ [range: 3 to $93 \mathrm{~d}$; interquartile range (IQR): 16 to 42 d], while for calves with BRD it was $43 \mathrm{~d}$ (range: 6 to $145 \mathrm{~d}$; IQR: 29 to $60 \mathrm{~d}$ )). Sixty-six percent of the total calves assessed had neither CD nor BRD, and $5 \%$ had both diseases. Effects of seasonal visit were detected for $\mathrm{CD}(P=0.002)$ but not for BRD $(P=$ 0.29). Summer visits had the lowest prevalence of CD cases compared with the other visits (Table 2). Median within-herd prevalence $(\mathrm{n}=17)$ of $\mathrm{CD}$ and $\mathrm{BRD}$ were 24\% (range: 8 to $46 \%$ ) and 14\% (range: 3 to $31 \%$ ), respectively. Median within-pen prevalence of $\mathrm{CD}$ and BRD were $17 \%$ (range: 0 to $100 \%$ ) and $11 \%$ (range: 0 to $60 \%$ ), respectively. Prevalence values by seasonal visit are shown in Tables 2 and 3.

The association between within-pen prevalence of $\mathrm{BRD}$ and $\mathrm{CD}$ was not significant $(P=0.13$; Figure 1$)$. 


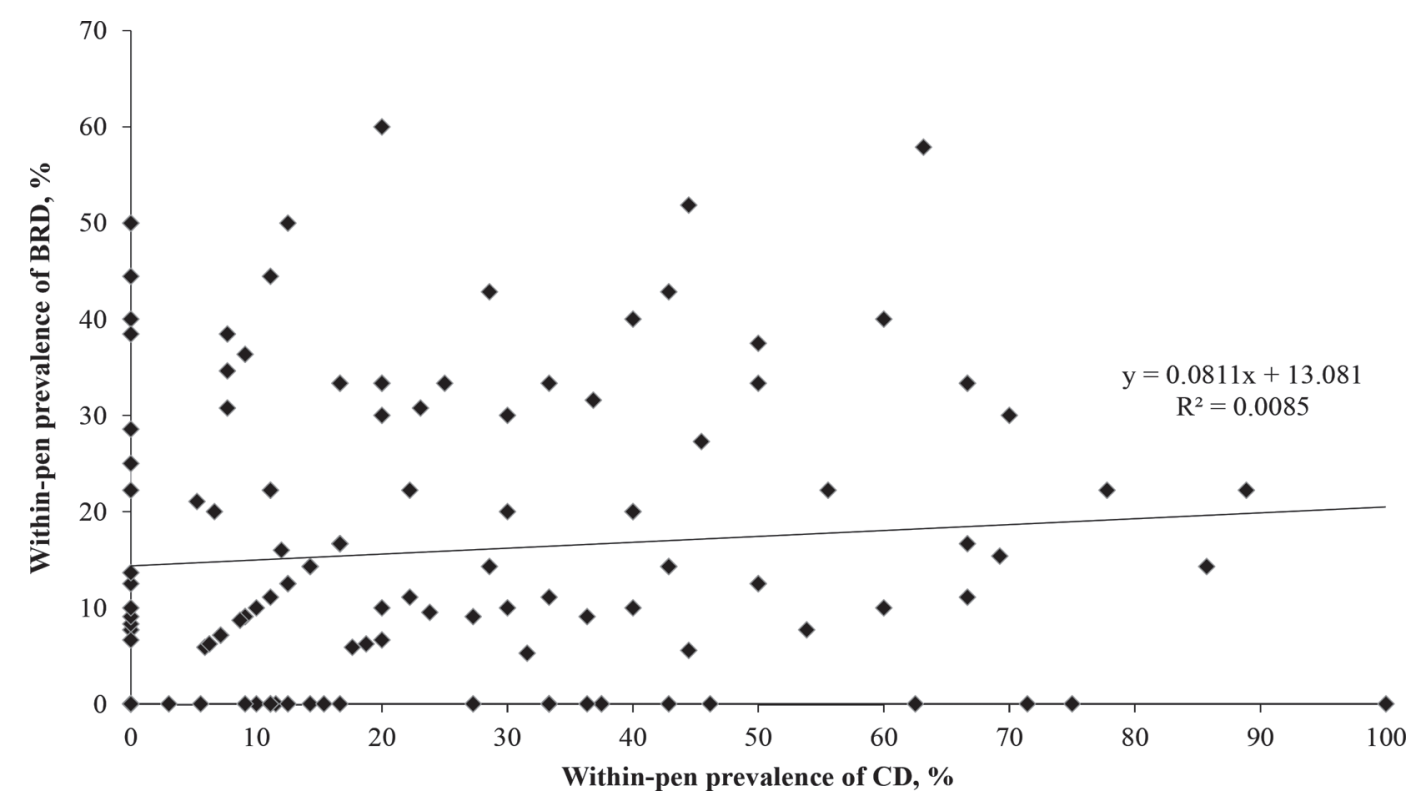

Figure 1. Scatterplot of within-pen prevalence of bovine respiratory disease (BRD) and calf diarrhea $(\mathrm{CD})$ on farms $(\mathrm{n}=17)$ raising calves in group pens with automated milk feeders in southern Ontario, Canada, that were visited 4 times, seasonally, over a 1-yr period.

Within-pen prevalence of CD was positively associated with within-pen prevalence of calves with abnormal navel (coefficient $=0.08 ; 95 \%$ CI: 0.05 to $0.11 ; P<$ 0.001 ) or with inadequate BCS (coefficient $=0.03 ; 95 \%$ CI: 0.02 to $0.04 ; P<0.001)$, whereas within-pen prevalence of BRD was positively associated with within-pen prevalence of calves with an abnormal attitude (coefficient $=0.04 ; 95 \%$ CI: 0.02 to $0.07 ; P=0.002$ ).

Treatments and Mortality. Based on producers' treatment and mortality records, the median herd-level incidence risk of being treated for CD at least once was $8 \%$ (range: 1 to $56 \%$ ). The median age at first treatment for CD was $12 \mathrm{~d}$ (range: 1 to $88 \mathrm{~d}$ ). The median herd-level incidence risk of being treated for BRD at least once was $37 \%$ (range: 2 to $89 \%$ ). The median age at first treatment for BRD was $27 \mathrm{~d}$ (range: 1 to $86 \mathrm{~d}$ ). The median herd-level mortality risk was $4 \%$ (range: 0 to $21 \%$ ).

\section{Factors Associated with Within-Pen Prevalence of $C D$}

The final models describing factors associated with $\mathrm{CD}$ at the pen level are summarized in Table 4. We found significant associations of seasonal visit and pen type with the prevalence of CD (Model 1). Regarding calving and newborn management, use of calving pens for additional purposes was associated with increased within-pen prevalence of CD. In addition, administration of both vitamin $\mathrm{E}$ and selenium to calves at birth was associated with decreased within-pen prevalence of
CD (Model 2). Pens in which calves were drinking milk with probiotics added to it had a lower prevalence of CD compared with pens in which calves either drank milk with no additives or drank milk with antibiotics added to it (Model 3). We did not find any significant association between the within-pen prevalence of $\mathrm{CD}$ and any factor regarding milk allowance (e.g., start and peak milk allowance, and latency to reach that peak).

There was an interaction $(P=0.02)$ between seasonal visits and bacteria counts (TBC) in milk samples taken from the mixing jar (Figure 2). Pens in which calves were drinking milk with $\mathrm{TBC} \geq 100,000 \mathrm{cfu} / \mathrm{mL}$ had significantly higher within-pen prevalence of CD compared with pens in which calves drank milk with TBC $<100,000 \mathrm{cfu} / \mathrm{mL}$, but only during the summer visits [odds ratio $(\mathbf{O R})=3.3 ; 95 \%$ CI: 1.3 to $8.5 ; P=$ 0.01]. We did not find any association between bacteria counts and AMF cleaning practices, but significant associations between frequency of AMF cleaning and

Table 2. Calf-level prevalence of diarrhea and respiratory disease from 17 dairy farms raising calves with automated milk feeders in southern Ontario for each of the 4 visits (one per season) to the farms

\begin{tabular}{lccc}
\hline $\begin{array}{l}\text { Seasonal } \\
\text { visit }\end{array}$ & $\begin{array}{c}\text { Calves, } \\
\text { no. }\end{array}$ & $\begin{array}{c}\text { Calf } \\
\text { diarrhea, } \%\end{array}$ & $\begin{array}{c}\text { Bovine respiratory } \\
\text { disease, \% }\end{array}$ \\
\hline Fall & 366 & 23 & 15 \\
Winter & 343 & 27 & 16 \\
Spring & 364 & 25 & 15 \\
Summer & 415 & 16 & 19 \\
Overall & 1,488 & 23 & 17 \\
\hline
\end{tabular}


Table 3. Within-herd- and within-pen-level prevalence of calf diarrhea and respiratory disease by visit (seasonal) from 17 dairy farms raising calves in group housing with automated milk feeders in southern Ontario

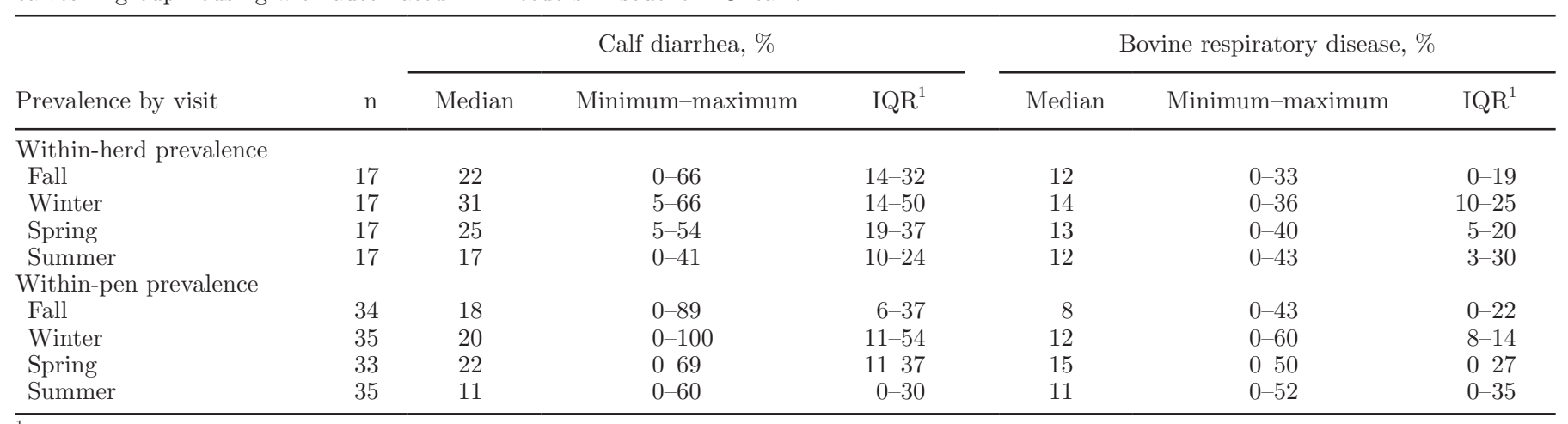

${ }^{1}$ Interquartile range.

within-pen prevalence of $\mathrm{CD}$ were found (Table 4, Model 4). Running the automatic cleaning of the AMF 3 times/day was associated with a reduced prevalence of CD compared with only running it once or twice. The frequency of cleaning hoses and replacing teats were detected as confounders, and therefore retained in the final model.

Regarding pen management and calf barn features, as the age of cattle sharing air with the calves in the group pens with the AMF increased, the prevalence of $\mathrm{CD}$ also increased. Furthermore, we detected a negative association between the frequency of adding bedding and the prevalence of CD (Table 4, Model 5). The frequency of removing all bedding was detected as confounder and therefore retained in the final model.

\section{Factors Associated with Within-Pen Prevalence of BRD}

The final models describing factors associated with BRD at the pen-level are summarized in Table 5 . Regarding calving and newborn management (Model 2 ), we found an association between the use of calving pens for additional purposes and increased within-pen prevalence of BRD (the number of days that calves were fed colostrum confounded this relationship). Pens where calves had access to whole milk instead of milk replacer and pens where calves were drinking milk with at least $13 \%$ TS compared with those $<10 \%$ TS had a significantly lower prevalence of BRD (Model 3).

Regarding pen management and calf barn features (Table 5, Model 4), pens with a mean age of introduction to the group pen $<8 \mathrm{~d}$ were associated with a reduced within-pen prevalence of BRD compared with pens with a mean age of introduction between 8 to 13 $\mathrm{d}$, or $>13 \mathrm{~d}$. In addition, as the depth of the wet bedding pack increased, so did the prevalence of BRD at the pen level. Similar to the findings for the prevalence of $\mathrm{CD}$, sharing air with older animals had a positive association with within-pen prevalence of BRD. Dry matter of the top layer of bedding was detected as confounder and therefore retained in the final model.

We did not find any association between within-pen prevalence of BRD and any factor regarding milk allowance (e.g., start and peak milk allowance, and latency to reach that peak) or AMF cleaning practices, including bacteria counts in milk.

\section{DISCUSSION}

This study is one of the first to provide information on associations between management practices and calf health at the pen level in a sample of farms using AMF to feed milk to group-housed calves. Multiple factors were found to be associated with either the prevalence of $\mathrm{CD}$ or BRD. In particular, quality of bedding and milk fed to calves and air shared with older cattle were found to be key factors because they were observed to be associated with both $\mathrm{CD}$ and BRD. These results highlight management practices that could be improved to successfully use group housing for calves using AMF. Our findings can help inform improvements in management practices in these systems, and guide decisionmaking of future adopters of AMF and group housing systems.

Overall, during the study period, 23 and $17 \%$ of the 1,488 calves across the 17 farms had CD and BRD, respectively. Previous research comparing manually fed calves housed individually and AMF-fed calves housed in groups found that group housing with AMF is detrimental to calf health, especially because of an increased risk of BRD (Svensson et al., 2003). However, calf-level prevalence values found in our study are similar to previously reported incidence risk estimates from dairy farms managing calves in individual pens in southwestern Ontario and Minnesota (CD: 20 and 23\%; BRD: 
Table 4. Final generalized linear regression models of groups of factors associated with within-pen prevalence of calf diarrhea on farms $(\mathrm{n}=$ 17) raising calves in group pens ${ }^{1}$ with automated milk feeders (AMF) in southern Ontario visited 4 times, seasonally, over 1-yr period, and the least squares means of the adjusted prevalence (AP)

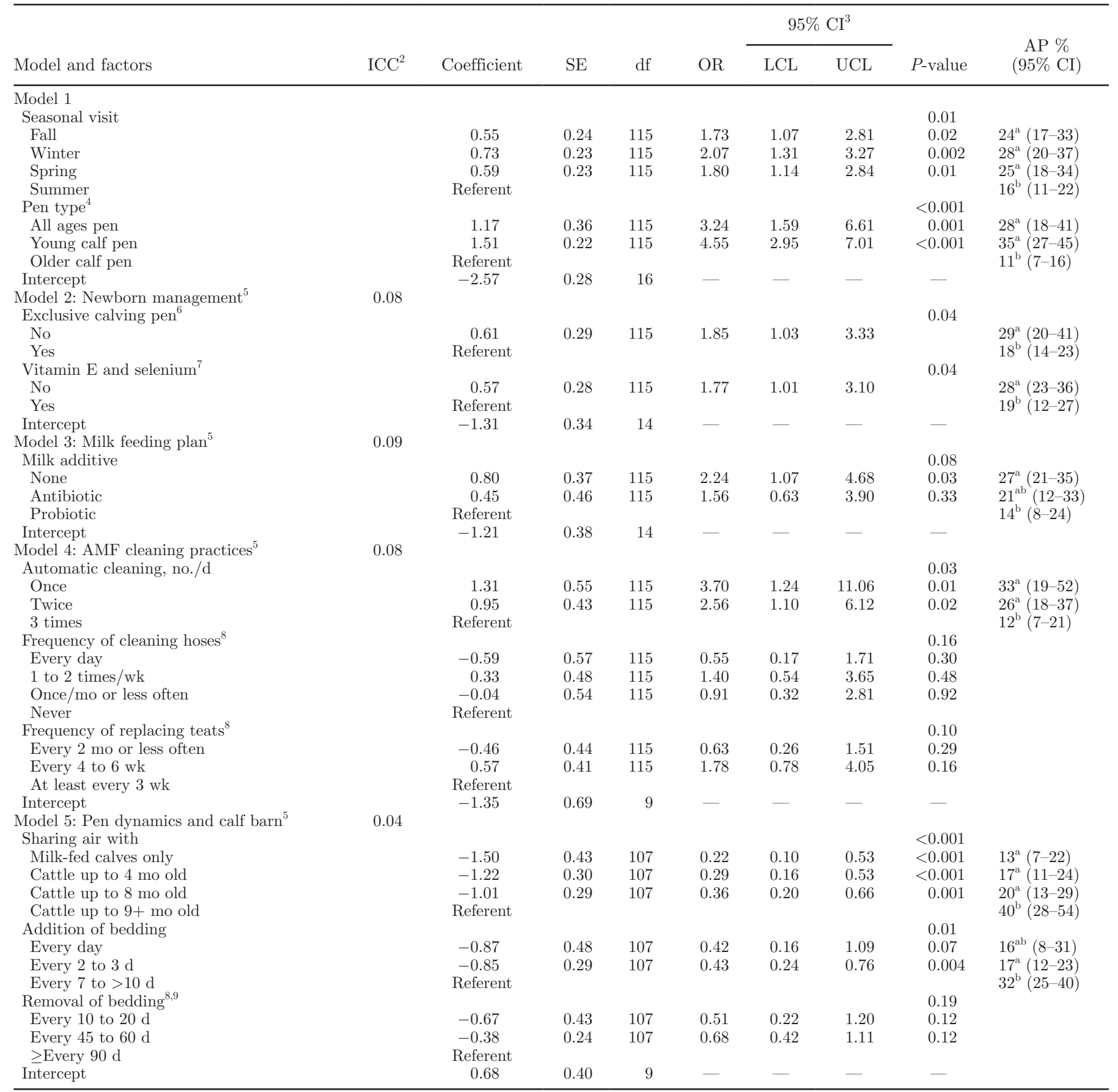

${ }_{\mathrm{a}, \mathrm{b}}$ Means within a model within a factor with different superscripts differ $(P \leq 0.05)$.

${ }^{1} 32$ to 35 pens were evaluated at each seasonal visit (137 observations in total).

${ }^{2}$ Intra-class correlation coefficient for each model.

${ }^{3}$ Confidence interval for the odds ratio (OR), lower (LCL) and upper (UCL) confidence limits.

${ }^{4}$ Young calf pen $=$ pen housing calves up to $30 \mathrm{~d}$ old approximately; older calf pen $=$ pen housing calves above $30 \mathrm{~d}$ old approximately, all ages pen $=$ pen housing all calves.

${ }^{5}$ Adjusted for seasonal visit and pen type.

${ }^{6}$ The use of calving pens exclusively for calving (not for sick cows).

${ }^{7}$ Administration of both vitamin $\mathrm{E}$ and selenium at birth.

${ }^{8}$ Retained in the final model because this variable acted as a confounder.

${ }^{9}$ Frequency of removing all bedding from the pen to add fresh bedding. 
15 and 22\%; Waltner-Toews et al., 1986; Windeyer et al., 2014, respectively). On the other hand, comparing exclusively with research done on farms using AMF, the calf-level prevalence of CD (23\%) and BRD $(17 \%)$ reported in the present study were higher than the calf-level incidence risk of $\mathrm{CD}$ and $\mathrm{BRD}$ reported by Svensson et al. (2003; 9 and 14\%, respectively) on Swedish farms. These differences could be related to dissimilarities in management and populations evaluated, as well as geographical differences; additionally, Svensson et al. (2003) were aware of the low incidences found and noted that this might have been related to low animal density and small farm size in Sweden (36 cows per herd at that time).

When looking at the median within-herd prevalence of CD and BRD (24 and 14\%, respectively), we found similar results to the BRD prevalence in a North American study done on farms housing and feeding calves individually (Lago et al., 2006: herd-level prevalence of $\mathrm{BRD}=14 \%$ ). The median within-herd prevalence of $\mathrm{CD}$ in the present study was higher than the median within-herd incidence risk of $10 \%$ reported by Windeyer et al. (2014), although the ranges were similar ( 8 to $46 \%$ vs. 0 to $44 \%$ ), indicating similar variability between farms. Differences from Windeyer et al. (2014) could be because theirs was an observational study conducted as part of a clinical vaccine trial and farms were a convenience sample; additionally, disease frequency was determined based on producer treatment records, which are known to have low sensitivity (Sivula et al., 1996).

At the pen level, our findings regarding median prevalence of CD (17\%) are similar to results reported by Svensson and Liberg (2006) who, in a randomized controlled trial on 9 Swedish farms raising calves in groups with AMF, also found a median within-pen incidence risk of CD of $17 \%$. Our prevalence of BRD at the pen level was lower than the incidence risk found by Svensson and Liberg (2006; 11 vs. 30\%, respectively). This difference could be related to the use of small groups, which Svensson and Liberg (2006) found to be protective for BRD. In our study, the median group size was 10 calves (IQR: 8 to 13 calves), whereas in Svensson and Liberg (2006), 50\% of their pens held 12 to 18 calves.

Our findings on disease frequency suggest that calf health on farms using group housing with AMF systems is not worse than that on farms housing calves individually. This assertion is also supported by the median within-herd incidence risk of mortality found in the present study (4\%), which was similar to mortality risk reported on farms mainly housing calves individually in Ontario and Minnesota (3\%; Windeyer et al., 2014) and on farms using group housing with AMF in Minnesota,

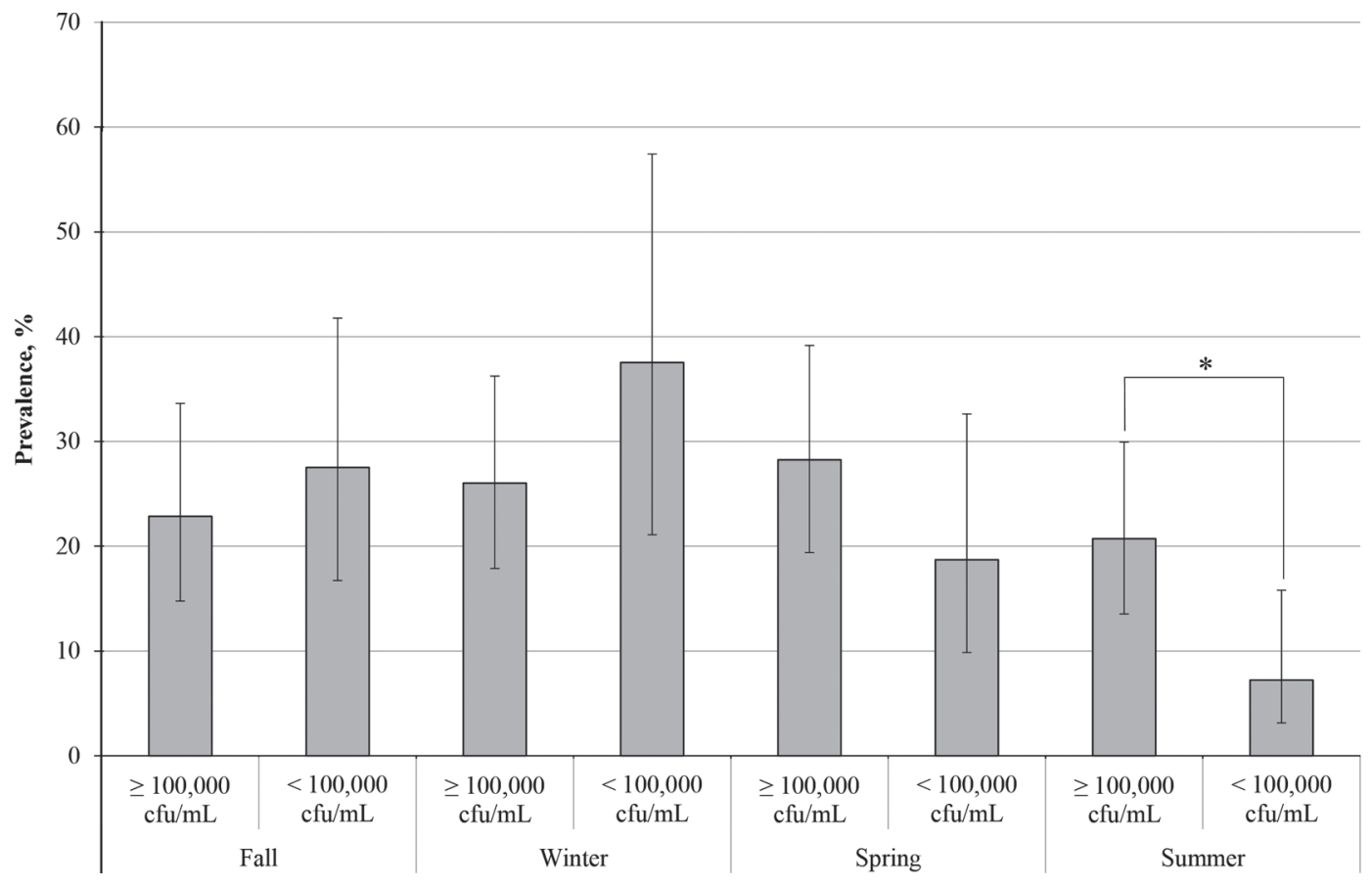

Figure 2. Association between within-pen prevalence of calf diarrhea (error bars are 95\% CI) and the interaction between seasonal visit and total bacteria counts (TBC) in milk samples taken from the mixing jar of automated milk feeders used to feed calves housed in groups on 17 dairy farms in southern Ontario, Canada. The TBC were considered acceptable or not acceptable if counts were $<100,000 \mathrm{cfu} / \mathrm{mL}$ or $\geq 100,000$ cfu/mL, respectively. ${ }^{*}$ Significant difference: $P<0.05$. 
Table 5. Final generalized linear regression models of group of factors associated with within-pen prevalence of bovine respiratory disease on farms $(\mathrm{n}=17)$ raising calves in group pens ${ }^{1}$ with automated milk feeders in southern Ontario visited 4 times, seasonally, over 1-yr period, and the least squares means of the adjusted prevalence (AP)

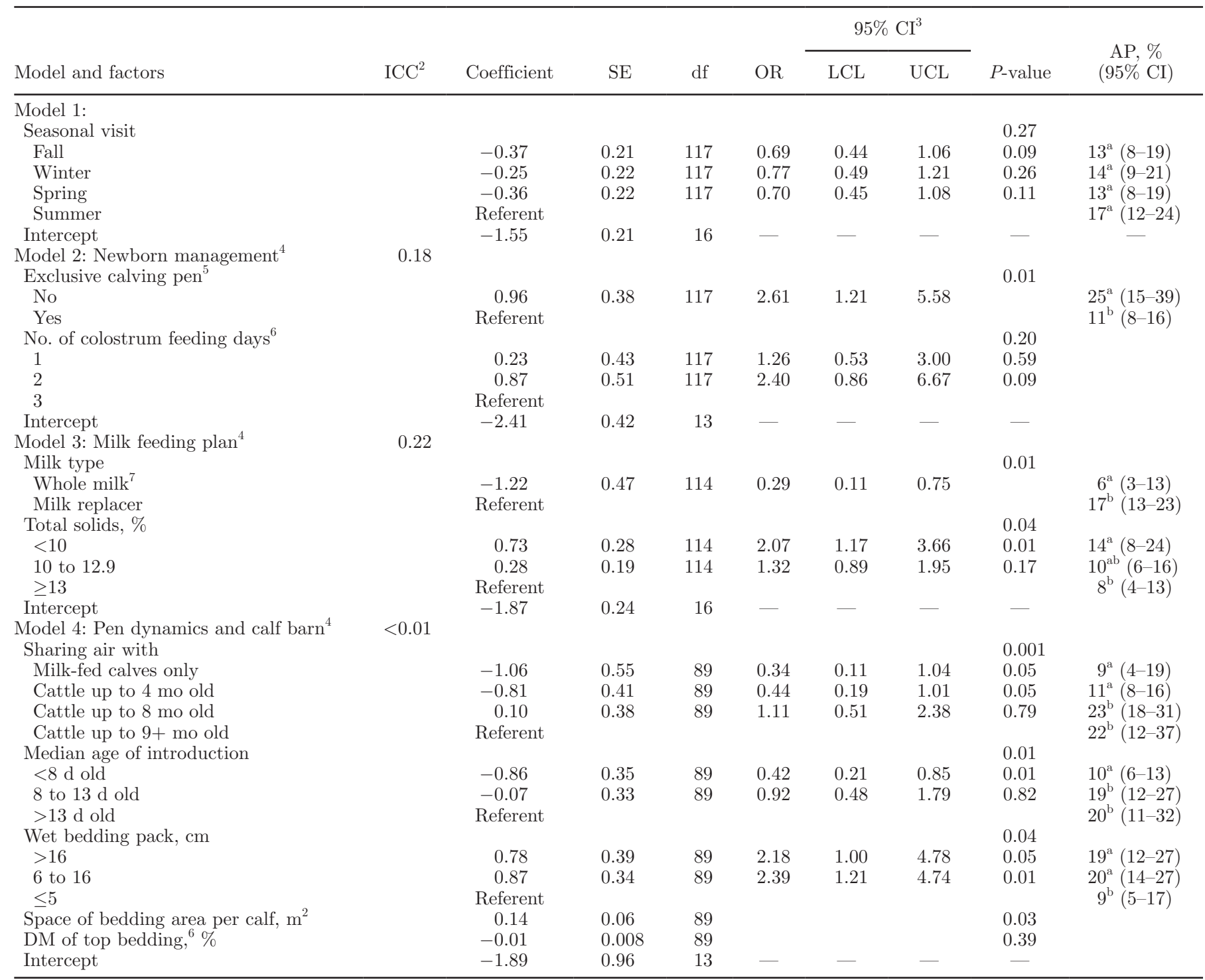

${ }_{\mathrm{a}, \mathrm{b}}$ Means within a model and factor with different superscripts differ $(P \leq 0.05)$.

${ }^{1} 32$ to 35 pens were evaluated at each seasonal visit (137 observations in total).

${ }^{2}$ Intraclass correlation coefficient for each model.

${ }^{3}$ Confidence interval for the odds ratio (OR), lower (LCL) and upper (UCL) confidence limits.

${ }^{4}$ Adjusted for seasonal visit.

${ }^{5}$ The use of calving pens exclusively for calving (not for sick cows).

${ }^{6}$ Retained in the final model because this variable acted as a confounder.

${ }^{7}$ Nonpasteurized.

northwest Iowa, and Wisconsin (4\%; Jorgensen and Endres, 2016). Moreover, mortality in the present study (4\%) was lower than that of a national United States report in which calves were mainly housed individually (8\%; USDA, 2007), and lower than that reported in a recent meta-analysis (5 to 11\%; Compton et al., 2017).
Reported disease frequency on farms is affected, among other factors, by the producer's diagnostic skill and treatment rates. We found that the median herd-level incidence risk of being treated for CD (8\%; obtained from producer records) was lower than the median herd-level prevalence of diarrhea (24\%) found 
across the study period, but not for BRD, which was higher in producer records (37 vs. 14\%). The difference found for CD could, first, be due to poor sensitivity of producers when identifying sick calves. For example, Sivula et al. (1996) found that the sensitivity of dairy producer diagnosis for enteritis was $58 \%$, meaning that some calves needing attention were not treated. The difference could have also been related to producers only treating calves with severe diarrhea. In the case of $\mathrm{BRD}$, despite the fact that sensitivity of producer diagnosis for BRD could be also low ( $56 \%$; Sivula et al., 1996), in the present study, some producers tended to treat the whole pen when there were signs of a pneumonia outbreak, which could explain the higher incidence risk of treatment.

\section{Common Factors Associated with Within-Pen Prevalence of $C D$ and $B R D$}

The use of calving pens for additional purposes was associated with increased within-pen prevalence of CD and BRD. Often, dairy farms have limited space to relocate and handle sick animals, leading to cows close to calving being housed with unhealthy cows (Hoe and Ruegg, 2006). Maternity or calving pens are the first place where calves can be infected with enteric and respiratory pathogens after birth (Maunsell and Donovan, 2008). For example, Fossler et al. (2005) found that the use of maternity pens as a hospital area was associated with 2-times-increased odds of Salmonella shedding in calves. Interestingly, Cobbold et al. (2006) found that when a farm exclusively separated the maternity area from the hospital area (as an intervention measure to reduce Salmonella in the herd), the prevalence of Salmonella isolated from the exclusive maternity pen after intervention decreased from 33 to $4 \%$. As Fossler et al. (2005) stated, implementing this practice could be a feasible change that producers could adopt to help reduce disease prevalence at the pen level where milkfed calves are housed.

Calf pens located in barns where older cattle were present had a higher prevalence of CD and BRD compared with those that were isolated from older cattle. This increased disease prevalence could be because older animals were a source of infection for the younger calves, which are less able to cope with pathogens in their environment (Radostits et al., 2007). For example, Virtala et al. (1999) found that the probability of developing pneumonia was 2 times higher for calves housed in the presence of adult cows than not, and similarly, Gulliksen et al. (2009) found that sharing a room with cows during the first week of life increased the risk of respiratory infection in calves (vs. calves housed in separate rooms). Another explanation for our findings could be inadequate ventilation and high animal density, which could trigger an increase in pathogens and ambient stressors (i.e., ammonia) in the environment, affecting calf health (Lago et al., 2006). For example, Mohammed et al. (1999) found an association between the lack of a well-ventilated calf barn and increased risk of infection with Cryptosporidium parvum. Other negative effects of housing calves with older cattle have been described. For example, Place et al. (1998) found that housing calves in a cow barn had detrimental effects on ADG; housing calves with older cattle could have increased susceptibility to disease, which is known to directly cause a decrease in weight gain (Donovan et al., 1998). Finally, another hypothesis to explain the association between increased disease prevalence and housing calves with older cattle could be the potential risk of transmission of pathogens from adult pens to calf pens by fomites (e.g., feed buckets, dirty boots, coveralls), as has been reported in the case of transmission of Cryptosporidium spp. between calves (Nydam and Mohammed, 2005).

Quality of bedding was associated with both CD and BRD prevalence. Within-pen prevalence of $\mathrm{CD}$ was lower in pens to which fresh bedding was added more frequently (every 2 to $3 \mathrm{~d}$ compared with every 7 to $>10 \mathrm{~d}$ ), whereas the depth of the wet bedding pack was positively associated with prevalence of BRD. Manure-saturated bedding is one of the primary sources of pathogens. McGuirk (2008) suggested that at least $7.6 \mathrm{~cm}$ (3 inches) of dry bedding should separate the calf from accumulated manure. For example, Mohammed et al. (1999) found that the risk of infection with Cryptosporidium parvum decreased when dirty bedding was removed and fresh bedding was added daily. Our findings suggest that adding fresh bedding on top without cleaning dirty spots would not be useful to reduce disease risk; dirty bedding should be removed frequently to prevent accumulation of waste and potential pneumonia pathogens from the bedding to be aerosolized (McGuirk, 2003).

We did not find any significant association between milk allowance factors and within-pen prevalence of disease. This supports previous research (Appleby et al., 2001; Bach et al., 2013) that evaluated the health of individually housed calves. The lack of significant associations regarding milk allowance and prevalence of disease in the present study might be real or could be because there was not enough difference in management of milk volumes for comparison. In $75 \%$ of the pens, peak milk allowance was at least $8 \mathrm{~L} / \mathrm{d}$ (median: $10 \mathrm{~L} / \mathrm{d}$ ), and only one pen had a peak of $6 \mathrm{~L} / \mathrm{d}$, which was the lowest value. 


\section{Factors Associated with Within-Pen Prevalence of $C D$}

Pens on farms that routinely administered both vitamin $\mathrm{E}$ and selenium to calves at birth had a significantly lower prevalence of CD. This supports the findings of Waldner and Rosengren (2009), who in an observational study on beef cow-calf farms in Alberta and Saskatchewan, Canada, found that calves born on farms that administered vitamin $\mathrm{E}$ and selenium at birth had a significantly lower risk of being treated for any disease $(\mathrm{OR}=0.5)$ or dying $(\mathrm{OR}=0.1)$ compared with calves from herds not implementing this practice. It is known that supplementation with vitamin $\mathrm{E}$ (Hughes, 2002) and selenium (McKenzie et al., 2002) is associated with enhanced antibody production and increased resistance to pathogens. Therefore, the administration of vitamin $\mathrm{E}$ and selenium at birth could have a truly direct effect in reducing CD; however, it could also be a surrogate measure for other unmeasured variables related to farmers who might pay more attention to detail regarding calf care.

In the present study, the prevalence of $\mathrm{CD}$ was 6 percentage points lower when prophylactic antibiotics were added to the milk fed through the AMF than when there were no additives in the milk. The prevalence of CD was 7 percentage points lower when probiotics were added than when antibiotics were added, and was 13 percentage points lower than when there were no additives in the milk. The use of prophylactic antibiotics in milk is mainly to reduce pathogenic flora and has been associated with decreased morbidity in calves (Berge et al., 2005). However, this practice can also increase antibiotic resistance (Pereira et al., 2011). On the other hand, probiotics are known to reduce the incidence and duration of diarrhea in calves (Timmerman et al., 2005). Therefore, probiotics could be implemented to reduce the prevalence of $\mathrm{CD}$ in pens with $\mathrm{AMF}$ and to decrease the use of prophylactic antibiotics. However, this study assessed whether antibiotics or probiotics were used, without further detail; more research is needed to better understand the issue, including the type of probiotic, timing, dosage, and so on.

Feeding equipment is another important source of enteric pathogens. If not cleaned properly, equipment can contaminate the milk fed to calves (McGuirk, 2008). In the present study, we found that programming the automatic cleaning of the feeder to run 3 times/day was associated with lower prevalence of CD at the pen level compared with less frequent cleaning. Similarly, James et al. (2017) recommended scheduling the automatic cleaning 4 times/day and before the times that calves most frequently suckle (Odde et al., 1985) or go to the feeder (Borderas et al., 2009) (at sunrise: 0500 to 0600 $\mathrm{h}$, from 1000 to $1300 \mathrm{~h}$, and at sunset: 1700 to $2100 \mathrm{~h}$ ) to lower bacteria counts in milk. However, little work is published regarding cleaning of AMF systems, and guidelines are needed for producers using or considering adopting this technology. We found that milk with a high content of bacteria was significantly associated with an increased prevalence of $\mathrm{CD}$, but only during the summer visit. Jorgensen et al. (2017) found that calves drinking milk with TBC >100,000 cfu/mL had a higher risk of receiving an abnormal score for attitude, ear position, and eye secretion, and a higher risk of having fever; however, they did not find a seasonal visit interaction with bacterial counts in milk. We do not have a clear explanation for the seasonal visit effect found in the present study; however, we speculate that during summer, calves might have experienced heat stress, causing immune suppression and, thus, increased susceptibility to pathogens and lower performance. For example, Place et al. (1998) found that calves born in summer tended to have lower ADG.

\section{Factors Associated with Within-Pen Prevalence of BRD}

We found that feeding whole milk instead of milk replacer was associated with a lower within-pen prevalence of BRD. This is similar to the findings of Godden et al. (2005), where calves fed pasteurized whole milk had 0.3 times lower risk of pneumonia compared with calves fed milk replacer. Godden et al. (2005) attributed the advantage of feeding whole milk to the higher nutrient and immune factor content compared with milk replacer. We found that a low TS percentage $(<10 \%)$ in milk (either whole milk or milk replacer) was associated with an increased within-pen prevalence of BRD compared with $>13 \%$. The percentage of TS in milk averages 12.5 to $13 \%$ (CDIC, 2017). Milk or milk replacer fed to calves should have similar content of solids; McGuirk (2015) specifically implied that nutritional concern increases when TS percentage is $<10 \%$, and our findings support this.

Another finding of the present study was that a mean age of introduction to the group pen with the AMF (mean for the pen) $<8 \mathrm{~d}$ was associated with a reduced prevalence of BRD compared with a mean age $>13 \mathrm{~d}$ old. In contrast, based on their findings, Svensson and Liberg (2006) recommended that age at introduction be at least $2 \mathrm{wk}$ to reduce the risk of BRD. Our hypothesis for this finding is that it might still be confounded by the daily milk allowance offered to calves during the period from birth to the day of introduction to the group with AMF, even though daily milk allowance before introduction was not a significant factor in the model. The majority of farms in this study fed restricted milk 
volumes before introduction to the AMF (median: 6 $\mathrm{L} / \mathrm{d}$ ), and the lack of variation in this variable (IQR: 5 to $8 \mathrm{~L} / \mathrm{d}$ ) might explain the lack of significance in the model. Following the stated hypothesis, we assumed that the longer it took for calves to be introduced to the group with AMF (which allowed calves to drink higher milk volumes), the longer calves would have been under a restricted milk diet, which is associated with persistent hunger, reduced nutrient intake, lower ADG (Thomas et al., 2001; Khan et al., 2011; Rosenberger et al., 2017), and higher risk for BRD relapse in individually housed calves (Bach et al., 2013). Therefore, we suggest that if introduction to the group is going to be delayed, calves should have access to high milk allowances immediately after colostrum feeding.

\section{Limitations}

This study was constrained by the fact that participant farms were a convenience sample, not a random sample, from the target population (dairy farms using AMF to feed milk to group-housed calves). This type of enrollment could have led to some selection bias, which might have caused a deviation of our estimates from the true values in the target population. Another limitation of this study was that we used prevalence as the measure of disease frequency, rather than incidence risk, because it was not economically or logistically feasible to visit each farm more often to follow calves during the entire milk-feeding period. Therefore, causal inferences cannot be made regarding risk factors identified in this study (Dohoo et al., 2009). In addition, by using prevalence based on quarterly visits, we likely underestimated the presence of disease, because the durations of $\mathrm{CD}$ and $\mathrm{BRD}$ are much shorter than the interval between our visits (Waltner-Toews et al., 1986; McGuirk, 2008). Because of concerns for the quality and consistency of detecting and recording disease in calves, we elected not to base our assessments on producer-recorded disease incidence.

Logistically, there was a limit to the number of farms, and thus pens, that we could include in the study. This relatively small sample size could have limited the statistical power of the analysis and increased the possibility of Type II error. Farm recruitment was further constrained by logistics in terms of the limited number of farms using AMF in Ontario and willingness to participate in the study.

\section{CONCLUSIONS}

Identification of factors associated with within-pen prevalence of health problems of group-housed calves fed through AMF is an essential step toward improving management practices and calf performance in farms currently using AMF and in guiding decision-making of future adopters. Prevalence of CD and BRD on farms using group housing with AMF systems was similar to previously reported disease frequency on farms using individual housing and feeding to raise calves. Thus, calf health is more dependent on management than on a type of system per se. Having exclusive calving pens and isolating calves from older cattle (exclusive calf nurseries) were key factors associated with reduced prevalence of $\mathrm{CD}$ and BRD. Poor quality of milk fed to calves, in terms of low percentage of TS and high bacterial counts, was also found to be associated with increased prevalence of $\mathrm{BRD}$ and $\mathrm{CD}$, respectively. Other management factors, such as the use of vitamin $\mathrm{E}$ and selenium and probiotics, maintaining clean and dry bedding, and daily cleaning of the feeder, as part of routine calf management practice were observed to be protective.

\section{ACKNOWLEDGMENTS}

This research was funded by Dairy Farmers of Canada (Ottawa, ON, Canada) as part of the Dairy Research Cluster 2 program. The first author also thanks the Administrative Department of Science, Technology and Innovation-Colciencias (Bogota, Cundinamarca, Colombia) for the $\mathrm{PhD}$ scholarship granted. The authors also thank the students who volunteered during data collection stages: Heidi Eccles, Mohamed Ibrahim, Amanda Armstrong, Allison Moorman, Sophia Marin, Danielle Fawcett, Melissa Speirs, Tanya Wilson (University of Guelph, Guelph, ON, Canada); Jose A. Bran (Universidade Federal de Santa Catarina, Florianópolis, Brazil); Ramiro Rearte (Universidad de La Plata, La Plata, Argentina); and Rolnei R. Daros (University of British Columbia, Vancouver, BC, Canada). Special thanks go to William Sears (statistical consultant, University of Guelph, Guelph, ON, Canada) for his patience and guidance with SAS; and to Matt Jorgensen (University of Minnesota, St. Paul, MN) for sharing his knowledge and experience with farms with automated milk feeders in the US Midwest, and to the participating dairy producers, their families, and their staff for allowing us to go into their farms and for all their involvement, help, and time during the year the study lasted.

\section{REFERENCES}

Abramson, J. H. 2011. WINPEPI updated: Computer programs for epidemiologists, and their teaching potential. Epidemiol. Perspect. Innov. 8:1.

Appleby, M. C., D. M. Weary, and B. Chua. 2001. Performance and feeding behaviour of calves on ad libitum milk from artificial teats. 
Appl. Anim. Behav. Sci. 74:191-201. https://doi.org/10.1016/ S0168-1591(01)00171-X.

Bach, A., M. Terre, and A. Pinto. 2013. Performance and health responses of dairy calves offered different milk replacer allowances. J. Dairy Sci. 96:7790-7797. https://doi.org/10.3168/jds.2013-6909.

Berge, A. C. B., P. Lindeque, D. A. Moore, and W. M. Sischo. 2005. A clinical trial evaluating prophylactic and therapeutic antibiotic use on health and performance of preweaned calves. J. Dairy Sci. 88:2166-2177. https://doi.org/10.3168/jds.S0022-0302(05)72892 -7 .

Borderas, T. F., A. M. B. de Passillé, and J. Rushen. 2009. Feeding behavior of calves fed small or large amounts of milk. J. Dairy Sci. 92:2843-2852. https://doi.org/10.3168/jds.2008-1886.

Callan, R. J., and F. B. Garry. 2002. Biosecurity and bovine respiratory disease. Vet. Clin. North Am. Food Anim. Pract. 18:57-77. https://doi.org/10.1016/S0749-0720(02)00004-X.

CDIC (Canadian Dairy Information Centre). 2017. Dairy facts and figures. Milk utilization and sales. Report D084. Accessed Jun. 1, 2017. http://aimis-simia-cdic-ccil.agr.gc.ca/rp/index-eng.cfm ?action $=\mathrm{pR} \& \mathrm{r}=237 \& \mathrm{pdctc}=$.

Cobbold, R. N., D. H. Rice, M. A. Davis, T. E. Besser, and D. D. Hancock. 2006. Long-term persistence of multi-drug-resistant Salmonella enterica serovar Newport in two dairy herds. J. Am. Vet. Med. Assoc. 228:585-591. https://doi.org/10.2460/javma.228.4 .585 .

Compton, C. W. R., C. Heuer, P. T. Thomsen, T. E. Carpenter, C. V. C. Phyn, and S. MacDougall. 2017. Invited review: A systematic literature review and meta-analysis of mortality and culling in dairy cattle. J. Dairy Sci. 100:1-16. https://doi.org/10.3168/jds .2016-11302

Dairy Research Cluster. 2011. Animal comfort tool. Stall wetness. Accessed Feb. 3, 2017. https://www.dairyresearch.ca/animal-comfort -tool.php.

Dohoo, I., W. Martin, and H. Stryhn. 2009. Veterinary Epidemiologic Research. VER Inc., Charlottetown, Prince Edward Island, Canada.

Donovan, G. A., I. R. Dohoo, D. M. Montgomery, and L. Bennett. 1998. Calf and disease factors affecting growth in female Holstein calves in Florida, USA. Prev. Vet. Med. 33:1-10. https://doi.org/ 10.1016/S0167-5877(97)00059-7.

Endres, M. I. 2013. Management and housing of automated calf feeders in the Midwest US. Pages 97-100 in Proc. Precision Dairy Conference and Expo: A Conference on Precision Dairy Technologies, Univ. Minnesota, Rochester. http://www.precisiondairyfarming .com/2015/wp-content/uploads/2015/08/2013-Precision-Dairy -Proceedings.pdf.

Fossler, C. P., S. J. Wells, J. B. Kaneene, P. L. Ruegg, L. D. Warnick, J. B. Bender, L. E. Eberly, S. M. Godden, and L. W. Halbert. 2005. Herd-level factors associated with isolation of Salmonella in a multi-state study of conventional and organic dairy farms II. Salmonella shedding in calves. Prev. Vet. Med. 70:279-291. https:// doi.org/10.1016/j.prevetmed.2005.04.002.

Godden, S. M., J. P. Fetrow, J. M. Feirtag, L. R. Green, and S. J. Wells. 2005. Economic analysis of feeding pasteurized nonsaleable milk versus conventional milk replacer to dairy calves. J. Am. Vet. Med. Assoc. 226:1547-1554. https://doi.org/10.2460/javma.2005 .226 .1547 .

Gulliksen, S. M., E. Jor, I. Lie, T. Løken, J. Akerstedt, and O. Østeràs. 2009. Respiratory infections in Norwegian dairy calves. J. Dairy Sci. 92:5139-5146. https://doi.org/10.3168/jds.2009-2224.

Hoe, F. G. H., and P. L. Ruegg. 2006. Opinions and practices of Wisconsin dairy producers about biosecurity and animal well-being. J. Dairy Sci. 89:2297-2308. https://doi.org/10.3168/jds.S0022 $-0302(06) 72301-3$.

Hughes, D. A. 2002. Antioxidant vitamins and immune function. Chapter 9, pages 176-178 in Nutrition and Immune Function. P. C. Calder, C. J. Field, and H. S. Gill, ed. CAB International, Wallingford, UK.

James, B., K. Machado, and A. Dietrich. 2017. Group housing systems for calves, facilities, equipment, protocols, and personnel. In Proc.
Western Dairy Management Conference, Reno, NV. http://wdmc .org/2017/James.pdf.

Jorgensen, M. W., A. Adams-Progar, A. M. de Passille, J. Rushen, S. M. Godden, H. Chester-Jones, and M. I. Endres. 2017. Factors associated with dairy calf health in automated feeding systems in the Upper Midwest of the United States. J. Dairy Sci. 100:5675-5686. https://doi.org/10.3168/jds.2016-12501.

Jorgensen, M. W., and M. I. Endres. 2016. Risk factors for calf mortality on farms using automated feeders in the Midwest USA. J. Dairy Sci. 99(E-Suppl. 1):582. (Abstr.)

Khan, M. A., D. M. Weary, and M. A. G. von Keyserlingk. 2011. Invited review: Effects of milk ration on solid feed intake, weaning, and performance in dairy heifers. J. Dairy Sci. 94:1071-1081. https://doi.org/10.3168/jds.2010-3733.

Lago, A., S. M. McGuirk, T. B. Bennet, N. B. Cook, and K. V. Nordlund. 2006. Calf respiratory disease and pen microenvironments in naturally ventilated calf barns in winter. J. Dairy Sci. 89:40144025. https://doi.org/10.3168/jds.S0022-0302(06)72445-6.

Lundborg, G. K., P. A. Oltenacu, D. O. Maizon, E. C. Svensson, and P. G. A. Liberg. 2003. Dam-related effects on heart girth at birth, morbidity and growth rate from birth to 90 days of age in Swedish dairy calves. Prev. Vet. Med. 60:175-190. https://doi.org/10.1016/ S0167-5877(03)00106-5.

Lundborg, G. K., E. C. Svenssona, and P. A. Oltenacu. 2005. Herdlevel risk factors for infectious diseases in Swedish dairy calves aged 0-90 days. Prev. Vet. Med. 68:123-143. https://doi.org/10 .1016/j.prevetmed.2004.11.014.

Maunsell, F., and G. A. Donovan. 2008. Biosecurity and risk management for dairy replacements. Vet. Clin. North Am. Food Anim. Pract. 24:155-190. https://doi.org/10.1016/j.cvfa.2007.10.007.

McGuirk, S. M. 2003. Solving calf morbidity and mortality problems. Preconvention Seminar 7: Dairy Herd Problem Investigation Strategies. Am. Assoc. Bovine Pract. 36th Annu. Conf., Columbus, OH. https://www.vetmed.wisc.edu/dms/fapm/fapmtools/8calf/ calfmorbid.pdf.

McGuirk, S. M. 2008. Disease management of dairy calves and heifers. Vet. Clin. North Am. Food Anim. Pract. 24:139-153. https://doi .org/10.1016/j.cvfa.2007.10.003.

McGuirk, S. M. 2015. Managing the environment of dairy calves to maximize health. Pages 11-22 in Proc. Calf and Heifer Congress: Manage what matters, East Syracuse, NY. https://nydairyadmin .cce.cornell.edu/uploads/doc_300.pdf.

McGuirk, S. M., and M. Collins. 2004. Managing the production, storage, and delivery of colostrum. Vet. Clin. North Am. Food Anim. Pract. 20:593-603. https://doi.org/10.1016/j.cvfa.2004.06.005.

McGuirk, S. M., and S. F. Peek. 2014. Timely diagnosis of dairy calf respiratory disease using a standardized scoring system. Anim. Health Res. Rev. 15:145-147. https://doi.org/10.1017/ S1466252314000267.

McKenzie, R. D., J. R. Arthur, S. M. Miller, T. S. Rafferty, and G. J. Beckett. 2002. Selenium and the immune system. Chapter 12, pages 235-241 in in Nutrition and Immune Function. P. C. Calder, C. J. Field, and H. S. Gill, ed. CAB International, Wallingford, UK.

Medrano-Galarza, C., S. J. LeBlanc, T. J. DeVries, A. Jones-Bitton, J. Rushen, A. M. de Passillé, and D. B. Haley. 2017a. A survey of dairy calf management practices among farms using manual and automated milk feeding systems in Canada. J. Dairy Sci. 100:6872-6884. https://doi.org/10.3168/jds.2016-12273.

Medrano-Galarza, C., S. J. LeBlanc, T. J. DeVries, A. Jones-Bitton, J. Rushen, A. M. de Passillé, and D. B. Haley. 2017b. Producer perceptions of manual and automated milk feeding systems for dairy calves. Can. J. Anim. Sci. https://doi.org/10.1139/CJAS $-2017-0038$.

Mohammed, H. O., S. E. Wade, and S. Schaaf. 1999. Risk factors associated with Cryptosporidium parvum infection in dairy cattle in southeastern New York State. Vet. Parasitol. 83:1-13. https://doi .org/10.1016/S0304-4017(99)00032-1.

Nydam, D. V., and H. O. Mohammed. 2005. Quantitative risk assessment of Cryptosporidum species infection in dairy calves. J. Dairy Sci. 88:3932-3943. https://doi.org/10.3168/jds.S0022 $-0302(05) 73079-4$. 
Odde, K. G., G. H. Kiracofe, and R. R. Schalles. 1985. Suckling behavior in range beef calves. J. Anim. Sci. 61:307-309. https://doi.org/ $10.2527 /$ jas $1985.612307 \mathrm{x}$.

Pennsylvania State University. 2007. Determining pasture yield. Information and Communication Technologies in the College of Agricultural Sciences. PennState Extension. Accessed Jun. 3, 2017. http://extension.psu.edu/publications/uc197/extension _publication_file.

Pereira, R. V. V., T. M. A. Santos, M. L. Bicalho, L. S. Caixeta, V. S. Machado, and R. C. Bicalho. 2011. Antimicrobial resistance and prevalence of virulence factor genes in fecal Escherichia coli of Holstein calves fed milk with and without antimicrobials. J. Dairy Sci. 94:4556-4565. https://doi.org/10.3168/jds.2011-4337.

Place, N. T., A. J. Heinrichs, and H. N. Erb. 1998. The effects of disease, management, and nutrition on average daily gain of dairy heifers from birth to four months. J. Dairy Sci. 81:1004-1009. https://doi.org/10.3168/jds.S0022-0302(98)75661-9.

Radostits, O. M., C. Gay, K. Hinchcliff, and P. Constable. 2007. Veterinary Medicine: A Textbook of the Disease of Cattle, Sheep, Pigs, Goats, and Horses. 10th ed. Elsevier Saunders, New York, NY.

Rosenberger, K., J. H. C. Costa, H. W. Neave, M. A. G. von Keyserlingk, and D. M. Weary. 2017. The effect of milk allowance on behavior and weight gains in dairy calves. J. Dairy Sci. 100:504-512. https://doi.org/10.3168/jds.2016-11195.

SAS Institute. 2017. The PLM procedure. SAS/STAT 9.3 User's guide. SAS Institute Inc., Cary, NC. https://support.sas.com/ documentation/cdl/en/statug/63962/HTML/default/viewer.htm \#statug_plm_a0000000118.htm

Schabenberger, O. 2005. Introducing the GLIMMIX procedure for Generalized Linear Mixed Models. Paper 196-30 in SUGI 30 Proceedings, Philadelphia, PA. SAS Institute Inc., Cary, NC. http:// www2.sas.com/proceedings/sugi30/196-30.pdf.

Sivula, N. J., T. R. Ames, W. E. Marsh, and R. E. Werdin. 1996. Descriptive epidemiology of morbidity and mortality in Minnesota dairy heifer calves. Prev. Vet. Med. 27:155-171. https://doi.org/10 .1016/0167-5877(95)01000-9.

Stull, C., and J. Reynolds. 2008. Calf welfare. Vet. Clin. North Am. Food Anim. Pract. 24:191-203. https://doi.org/10.1016/j.cvfa 2007.12.001.

Svensson, C., and P. Liberg. 2006. The effect of group size on health and growth rate of Swedish dairy calves housed in pens with automatic milk-feeders. Prev. Vet. Med. 73:43-53. https://doi.org/10 .1016/j.prevetmed.2005.08.021.

Svensson, C., K. Lundborg, U. Emanuelson, and S.-O. Olsson. 2003. Morbidity in Swedish dairy calves from birth to 90 days of age and individual calf-level risk factors for infectious diseases. Prev. Vet. Med. 58:179-197. https://doi.org/10.1016/S0167-5877(03)00046 -1 .

Thomas, T. J., D. M. Weary, and M. C. Appleby. 2001. Newborn and 5-week-old calves vocalize in response to milk deprivation. Appl. Anim. Behav. Sci. 74:165-173. https://doi.org/10.1016/S0168 -1591(01)00164-2.

Timmerman, H. M., L. Mulder, H. Everts, D. C. van Espen, E. van der Wal, G. Klaassen, S. M. G. Rouwers, R. Hartemink, F. M.
Rombouts, and A. C. Beynen. 2005. Health and growth of veal calves fed milk replacers with or without probiotics. J. Dairy Sci. 88:2154-2165. https://doi.org/10.3168/jds.S0022-0302(05)72891 $-5$.

UCLA. 2017. Analyzing and visualizing interactions in SAS. UCLAINDRE (Institute for Digital Research and Education). https:// stats.idre.ucla.edu/sas/seminars/analyzing-and-visualizing -interactions/.

University of Wisconsin-Madison. 2013a. Data collection tools. Calf health scoring chart. Food Animal Production Medicine. University of Wisconsin-Madison. Accessed Feb. 3, 2017. http://www .vetmed.wisc.edu/dms/fapm/fapmtools/8calf/calf_health_scoring _chart.pdf.

University of Wisconsin-Madison. 2013b. Clinical information and forms-calves. Brix readings for milk replacer solution standards. Food Animal Production Medicine, University of Wisconsin-Madison. Accessed Feb. 3, 2017. https://www.vetmed.wisc.edu/dms/ fapm/fapmtools/8calf/BrixRefrac.pdf.

USDA. 2007. Heifer Calf Health and Management Practices on U.S. Dairy Operations. United States Department of Agriculture. Section I. Population estimates. Mortality and Carcass Disposal. Animal and Plant Health Inspection Service. Veterinary Services. National Animal Health Monitoring System (USDA-APHIS-VS-CEAH-NAHMS). Fort Collins, CO. Accessed Jun. 3, 2017. https:// www.aphis.usda.gov/animal_health/nahms/dairy/downloads/ dairy07/Dairy07_ir_CalfHealth.pdf.

USDA. 2016. Dairy cattle management practices in the United States, 2014. United States Department of Agriculture. Animal and Plant Health Inspection Service. Veterinary Services. National Animal Health Monitoring System (USDA-APHIS-VS-CEAH-NAHMS). Fort Collins, CO. Accessed Aug. 6, 2016. https://www.aphis.usda .gov/animal_health/nahms/dairy/downloads/dairy14/Dairy14 _dr_PartI.pdf.

Virtala, A.-M. K., Y. T. Gröhn, G. D. Mechor, and H. N. Erb. 1999. The effect of maternally derived immunoglobulin $\mathrm{G}$ on the risk of respiratory disease in heifers during the first 3 months of life. Prev. Vet. Med. 39:25-37.

Waldner, C. L., and L. B. Rosengren. 2009. Factors associated with serum immunoglobulin levels in beef calves from Alberta and Saskatchewan and association between passive transfer and health outcomes. Can. Vet. J. 50:275-281.

Waltner-Toews, D., S. W. Martin, A. H. Meek, and I. McMillan. 1986. Dairy calf management, morbidity and mortality in Ontario Holstein herds. I: The data. Prev. Vet. Med. 4:103-124.

Wilson, L. L. J. L. Smith, D. L. Smith, D. L. Swanson, T. R. Drake, D. R. Wolfgang, and E. F. Wheeler. 2000. Characteristics of veal calves upon arrival, at 28 and 84 days, and at the end of the production cycle. J. Dairy Sci. 83:843-854. https://doi.org/10.3168/ jds.S0022-0302(00)74948-4.

Windeyer, M. C., K. E. Leslie, S. M. Godden, D. C. Hodgins, K. D. Lissemore, and S. J. LeBlanc. 2014. Factors associated with morbidity, mortality, and growth of dairy heifer calves up to 3 months of age. Prev. Vet. Med. 113:231-240. https://doi.org/10.1016/j .prevetmed.2013.10.019. 